Int. J. Dev. Biol. 57: 41-47 (2013)

doi: $10.1387 / \mathrm{ijdb} .120223 \mathrm{ma}$

\title{
Characterization of CXC-type chemokine molecules in early Xenopus laevis development
}

\author{
TOSHIYASU GOTO'1, TATSUO MICHIUE², YUZURU ITO³ and MAKOTO ASASHIMA*,2,3 \\ ${ }^{1}$ Department of Molecular Cell Biology, Medical Research Institute and School of Biomedical Science, Tokyo Medical \\ and Dental University, Tokyo, ${ }^{2}$ Department of Life Sciences (Biology), Graduate School of Arts and Sciences, The \\ University of Tokyo, Tokyo and ${ }^{3}$ Research Center for Stem Cell Engineering, National Institute of Advanced Industrial \\ Science and Technology (AIST), Tsukuba, Japan
}

\begin{abstract}
Chemokine molecules play important roles in the immune system. However, several chemokine molecules are expressed during early development before the immune system is established. Using reverse transcription-polymerase chain reaction (RT-PCR) and overexpression of chemokine molecules, we identified and characterized Xenopus laevis CXC-type chemokine ligands (XCXCL13L1, XCXCL13L2, XCXCLa, XCXCLb, XCXCLd, and XCXCLe) and receptors (XCXCR1/2, XCXCR3, XCXCR5, XCXCR6, and XCXCRa) during early development. The CXC-type ligands have low identity with genes for human CXC ligands (CXCL). With the exception of XCXCRa, the CXC receptors (CXCR) identified in the present study had high ( $40 \%-65 \%)$ identity with human CXCR genes. Although the expression patterns for the $C X C L$ and $C X C R$ genes differed, transcript levels for all genes were very low during early embryogenesis. Overexpression of XCXCL13L1, XCXCL13L2, XCXCLa, XCXCR3, XCXCR6, and XCXCRa interfered with gastrulation and neural fold closure. The results of the present study suggest that several chemokine molecules are related to cell movements during early morphogenesis.
\end{abstract}

KEY WORDS: chemokine, CXC receptor, CXC ligand, gastrulation, Xenopus laevis

\section{Introduction}

Chemokine ligands are considered cytokine molecules and, in mammals, have been investigated primarily in terms of their immunomodulatory role. Mammalian chemokines are divided into four families, namely CC-, CXC-, XC-, and CX3C-type chemokines, which contain 28, 17, 2, and 1 member, respectively (Laing and Secombes, 2004; Hiraoka et al., 2011). Chemokine receptors are members of the G-protein-coupled receptor (GPCR) family and have seven transmembrane structures. The chemokine receptors are also divided into four families according to ligand type: CC-, CXC-, XC-, and CX3C-type receptors, containing 10, 7, 1, and 1 member, respectively (Allen et al., 2007).

Seventeen CXC-type chemokines have been identified and characterized in mammals (Laing and Secombes, 2004). The CXC chemokines are further divided into two groups depending on the presence (+) or absence (-) of the tripeptide motif glutamic acid-leucine-arginine (ELR) at the $\mathrm{N}$-terminus of the first cysteine residue. The CXC ligands (CXCL) CXCL1, CXCL2, CXCL3, CXCL5, CXCL6, CXCL7, CXCL8, and CXCL15 belong to the ELR(+) group
(Romagnani et al., 2004; Wang et al., 2005). It has been reported that CXCL1-CXCL8 bind to the CXC receptor (CXCR) CXCR2, but a receptor for CXCL15 is yet to be unidentified (Zlotnik and Yoshie, 2000; Wang et al., 2005). Specifically, CXCR1 binds CXCL1, CXCL6, and CXCL8 (Zlotnik and Yoshie, 2000); CXCR3 and its alternatively splicing variant bind CXCL4, CXCL9, CXCL10, and CXCL11 (Zlotnik and Yoshie, 2000; Lasagni et al., 2003); CXCR4 binds CXCL12; CXCR5 binds CXCL13; CXCR6 binds CXCL16; and, CXCR7 binds CXCL11 and CXCL12 (Zlotnik and Yoshie, 2000; Naumann et al., 2010; Agostini et al., 2005). No receptors have been identified as yet for CXCL14 and CXCL17 (Hara and Tanegashima, 2012; Hiraoka et al., 2011).

Recent studies have revealed that several chemokine ligands and receptors have important roles in early embryogenesis in vertebrates before the immune system is established. For example, CXCL12/CXCR4 promotes directional movement of primordial germ cell (PGC) migration in zebrafish (Doitsidou et al., Abbreviations used in this paper: CXCL, CXC ligand; CXCR, CXC receptor; PGC,
primordial germ cell; RT-PCR, reverse transcription-polymerase chain reaction.

\footnotetext{
*Address correspondence to: Makoto Asashima. Department of Life Sciences (Biology), Graduate School of Arts and Sciences, The University of Tokyo, 3-8-1 Komaba, Meguro-ku, Tokyo 153-8902, Japan. Tel: +81-3-5454-6632. Fax: +81-3-5454-6698. e-mail: asashi@ bio.c.u-tokyo.ac.jp
} 
XCXCL13L1 MKYIAVLLCLALLMEGCSLITGFPWESLKTGKKCRCLKQTNK-RP SSFF-RIQVYPERFN

human CXCL13 MRFISTSLLLMLLVSSLSPVQG-VLEVYYTSLRCRCVQESSVFIPRRFIDRIQILPRGNG

XCXCL13L1 CRKKEVLVFLRTKHIICVDPEARWLOVMISNSHKKHNEKSENNT

$* \ldots * * . . * . . . * * . * * * . * * . * * . . . . *$.

human CXCL13 CPRKEIIVWKKNKSIVCVDPQAEWIQRMMEVLRKRSSSTLPVPVFKRKIP

$36.8 \%$ identities

B

XCXCL13L1 MKYIAVLLCLALLMEGCSLITGFPNESLKTGKKCRCLKQTNK-RPSSFF-RIQVYPERFN human CXCL13 MKFISTSLLLMLLVSSLSPVQG-VLEVYYTSLRCRCVQESSVEIPRRFIDRIQILPRGNG

XCXCL13L1 CRKKEVLVFLRTKHIICVDPEARWLQVMISNSHKRHNEKSENNT

human CXCL13 CPRKEIIVWKKNKSIVCVDPQAEWIQRMMEVLRKRSSSTLPVPVFKRKIP

$36.8 \%$ identities

XCXCR1/2 MSFNEDGSFFNDIDFSDIPTGEPTVISAPCK-STWVINKYFVVVVYALVFFLNVVGNS human CXCR1 MSNITDPQMWDFDDINFTGMPP--ADEDYSPCMLETTETLNKYVVIIAYALVFLLSLIGNS

XCXCR1/2 LVVLVIYNNKLKRSSTDVYLLHLAIADLLFATTLPFWAAYKAS QWVFGIFMCKAVSVLQE

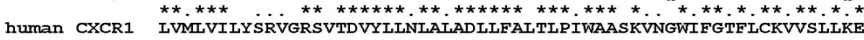

XCXCR1/2 VNFYSGILILACCISVDRYLAIVHATEAVTRKRHWVKFICLGIWIFSLVVSIPTLIFRTVF human CXCR1 VNFYSGILLLACISVDRYLAIVHATRTLTQKRHLVKFVCLGCWGLSMNLSLPFFIFRQAY

XCXCR1/2 KSPRDAYVCHDSIGNENTEDWMIILRIGRHLVGFFIPLLIMLFCYGGTIKTLYQTKSSQK

human CXCR1 HPNISSPVCYEVLGND-TAKWRMVLRILPHTFGFIVPLFVMLFCYGFTLRTIFKAHMG

XCXCR1/2 HRAMKVIFAVVL.AFLICWLPYNLTVIVDSLIMRTRFINETCEKREHLDAALSTTEIFGYTH

human CXCR1 HRAMRVIFAVVLIFLICWLPYNLVLIADTLMRTQVIQESCERRNIIGRALDATEILGFLH

XCXCR1/2 SCINPILYAFIGQKFWNSFIRILASKGIVNKSFI.ARYARGSTFSFGSTSGNTSNTI

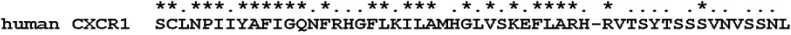

$$
55.8 \% \text { identities }
$$

XCXCR3 MQSETQDLPANMDFDGHRIYNADDFESSSPFYDY - KSSTETTDEAPCNLQTTVMFDRSF human CXCR3 MVLEVSDHQVLNDAEVAALLENFSSSYDYGENESDSCCTSPPCPQDFSLNFDRAF XCXCR3 LPAFYSIVFLLGMLGNVLVLVVLLQNRWRLQSTDIFLLHLALADILLVITILPFWATQAVS

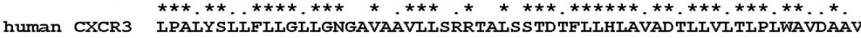
XCXCR3 GWTFGNVLCKMVASIFKINFYACTFLLVCISCDRYLSIVYAVQLYKKHRTHLVHWSCLIV human CXCR3 QWVFGSGLCKVAGALFNINFYAGALLIIACISFDRYLNIVHATQLYRRGPPARVTLTCLAV XCXCR3 WCLCIGLSIPDMVYYRVTYEPRANVTDCQPDFGHLDSKTWKISITFLYHIVGFLIPLCFM

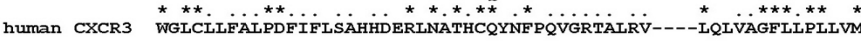
XCXCR3 VYCYTHIIHSLCQTHGFKKQKAILRVVIAVVVIFFLCWTPYNIVALIDTMNILNVLPDNCT

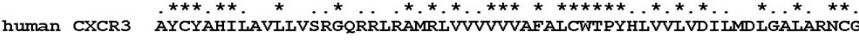
XCXCR3 TDSNIDIALSVTSGLCYFHSCLNPLIYAFVGAKFKMKLVELISSKLSCICPQIVKKYIKYN

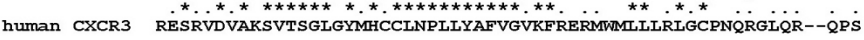
XCXCR3 PPAKPSTWSESGDTTVSAM

human CXCR3 SSRRDSSWSETSEASYSGI

44.8\% identities

XCXCR6 MTNNTEESEIIYYDEETSD SDHHMLH--DYILPVLYSVTCVTGLVGNLIIIIIYYAFYE

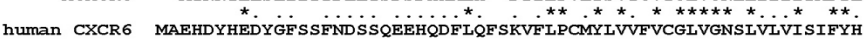
XCXCR6 KMRTLTDTFMVNLAMADIFFLCTLPFI.AYQVAQGWIFGEVMCKITRVVYRINLYCSMLII

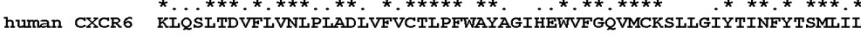
XCXCR6 TCITFDRFISITQAKKFNMYHSKKHSLGKLVCMIVWLVSLILIAVPQFKY-SVTSNENCFE

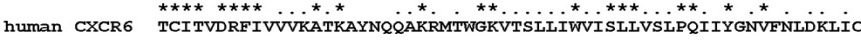
XCXCR6 VYDPPHLEVMVNSFQITVGVFIPLAAMIFCYTFIIKKLIFASNYQKHKSIKIIIFMVVMAF

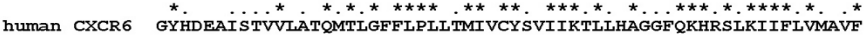
XCXCR6 IATQLPYNIGILCHVV----YKTFDKTF-MLITEAIAYMHACLNPILYFFVGVKFRKNFW human CXCR6 LLTQMPFNLMKFIRSTHWEYYAMTSFHYTIMVTEAIAYLRACLNPVLYAFVSLKFRKNFW XCXCR6 KILEDLRLAKPNMELSDNLKTTDRESKSIS SYMNTTEAISMNQI

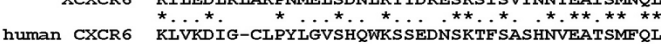

41.7\% identities

\author{
XCXCL13L2 MSMKHIAV-LSVIVLLAILHCIAGSLEPRLPGGRCKCFKQTNQFIKPNKLTRVEF

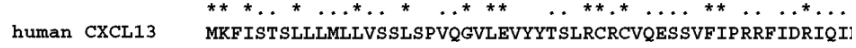 \\ XCXCL13L2 SCPQLECLVTLKNGEIVCVNPQAVWLQRLIAYLKEKSSAADSTPI \\ **. * .* **.****.***.**...*...**....* \\ human CXCL13 GCPRKEIIVWKKNKSIVCVDPQAEWIQRMMEVLRKRSSSTLPVPVERRKIP
}

$35.9 \%$ identities
XCXCL13L2 MSMKHIAV-LSVIVLLAILHCIAGSLEPRLPGGRCKCFKQTNQFIKPNKLTRVEFFPPGR
human CXCL13
$* * \ldots * \ldots * \ldots * \ldots * * * \ldots * * * \ldots * * \ldots \ldots * \ldots * *$ MKFISTSLLLMLLVSSLSPVQGVLEVYYTSLRCRCVQESSVFIPRRFIDRIQILPRGN

XCXCL13L2 SCPQLECLVTLKNGEIVCVNPQAVWLQRLIAYLKEKSSAADSTP human CXCL13 GCPRKEIIVWKKNKSIVCVDPQAEWIQRMMEVLRKRSSSTLPVPVFRRKIP

$35.9 \%$ identities

XCXCR1/2 MSFNEDGSFFNDIDFSDIPTGFPTVISAPCKSTWV-INKYFVVVVYALVF

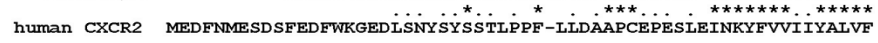
XCXCR1/2 FLNVVGNSLVVLVIYNNKLKRSSTDVYILHLAAIADLIFATTLPFWAAYKAS QWVFGIFMC

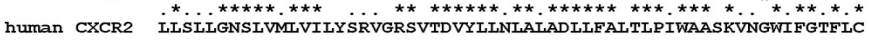
XCXCR1/2 KAVSVLQEVVNFYSGILILACISVDRYIAIVHATEAVTQKRHWVKFICLGIWIFSLVVSIP human CXCR2 KVVSLLKEVNFYSGILLLACISVDRYLAIVHATRTLTQKRYLVKFICLSIWGLSLILALIP XCXCR1/2 TLLFRTVFKSPRDAYVCHDSIGNENTEDWMIILRIGRHLVGFFIPLLIMLFCYGFTIKTI human CXCR2 V̈LLFRRTVYSSNVSPACYEDMGN-NTANWRMLLRILPQSFGFIVPLLIMLFCYGFTLRTL XCXCR1/2 YQTKSSQKHRAMKVIFAVVL.AFIICWLPYNLTVIVDSIMRTRFINETCEKREHIDAAALST human CXCR2 FKAHMGQKHRAMRVIFAVVLIFLLCWLPYNLVLIADTLMRTQVIQETCERRNHIDRALDA XCXCR1/2 TEIFGYTHSCINPILYAFIGQKFWNSFIRII_ASKGIVNKSFLARYARGSTESFGSTSGNT human CXCR2 $\begin{aligned} & \star * \star \\ & \text { TEILGILHSCLNPLIYAFIGQKFRHGLLKILAIHGLISKDSLPRDSR-PSF-VGSSSGHT }\end{aligned}$ $\mathrm{XCXCR} 1 / 2 \quad \mathrm{SNTL}$

human CXCR2 $\stackrel{\star \star \star \star *}{\text { STTL }}$

$58.3 \%$ identities

XCXCR5 MESTGFVLNNIEESDFLDFLI PDLNESNYEESLNDTSDFVCPETFQDEPLGTLVHFQRVF human CXCR5 XCXCR5 IPLVYTLVFILGFLGNSLVLLILIKFRRSRSTTENFLLHLALAADLLLLVTFPFAITESVA human CXCR5 VPVAYSLIFLLIGVIGNVLVLVILERHRQTRSSTETFLFHLAVADLLLVFILPFAVAEGSV XCXCR5 GWVFGRFICKLVGVISRVNFFCSNLLIGCISVDRYIAIIHAIHTFRSRRLVAVHLPCFGV

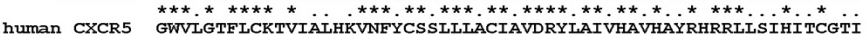
XCXCR5 WALCFLLSMPN-LF--VLEIQENGNVTTCTYHQSHFPSSRWWQTGRFLNHIVGFLVPLMI human CXCR5 WLVGFLLALPEILFAKVSQGHHNNSIPRCTFS SENQAETHAWFTSRFLYHVAGFLIPMLV XCXCR5 MGFCYAHIVTALCRS-PRLEKKKAVRLAILITVVFLLCWTPYNVTVEIDTLEQL-GLVQS human CXCR5 MGWCYVGVVHRLRQAQRRPQRQKAVRVAILVTSIFFLCWSPYHIVIFLDTLARLKAVDNT XCXCR5 CKVRKELPFAITVTEFIGSVHCCLNPIIYAFVGVKFRNDAIRILRKAGCFRSLISAVPLH

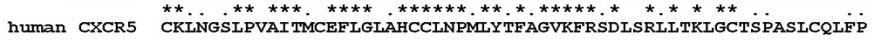
XCXCR5 FDRKSSATDSENGTUMYSF

human CXCR5 SWRRSSLSESENATSLTTF

\section{$47.7 \%$ identities}

Fig. 1. Alignments of the amino acid sequences of chemokine genes. The conserved amino acids are represented by asterisks (*). (A) Alignments between XCXCL13L1 or XCXCL13L2 and human CXCL13. (B) Alignments between the human chemokine receptors and their Xenopus homologs.

2002), and CXCR7 controls proper directional migration of PGC (Mahabaleshwar et al., 2008). In Xenopus, xSDF-1 $\alpha$, a homolog of CXCL12, and XCXCR4 contribute to the directional migration of mesendodermal cells during gastrulation (Fukui et al., 2007). Furthermore, expression of XCXCLC in the midline region during gastrulation and neurulation promotes lateral-medial directional tissue convergence (Goto and Asashima, 2011). In both chick and Xenopus embryos, tissue-specific expression patterns of CXCL14 
have been reported during early embryogenesis. However, many chemokine ligands and receptors remain uncharacterized in embryogenesis.

In the present study, we cloned the following CXC-type chemokine ligands from Xenopus laevis: CXCL13L1 (XCXCR13L1: GenBank/DDBJ Accession no. BG018851); CXCL13L2(XCXCL13L2: CF342082); CXCLa (XCXCLa: CB199271); CXCLb (XCXCLb: BC130085); CXCLd(XCXCLd:AW644053); and CXCLe (XCXCLe: CF548813). In addition, we cloned the CXCR1/2 (XCXCR1/2: AJ312936) receptor and identified four novel chemokine receptors: CXCR3 (XCXCR3: AB720054); CXCR5 (XCXCR5: AB720055); CXCR6 (XCXCR6:AB720056); and CXCRa (XCXCRa:AB720057). The nomenclature of these chemokine genes is based on the Cytokine Family Database (http://cmbi.bjmu.edu.cn/cmbidata/cgf/ CGF_Database/cytokine.medic.kumamoto-u.ac.jp/default.htm). The expression patterns of these chemokine genes and their effects on early embryogenesis were evaluated.

\section{Results}

\section{Isolation of Xenopus laevis CXCL and CXCR genes}

Full-length cDNA fragments were obtained from Stage 10 embryos for XCXCR13L1, XCXCL13L2, XCXCLa, XCXCLb, XCXCLd, XCXCLe, XCXCR1/2, XCXCR3, XCXCR5, XCXCR6, and

A

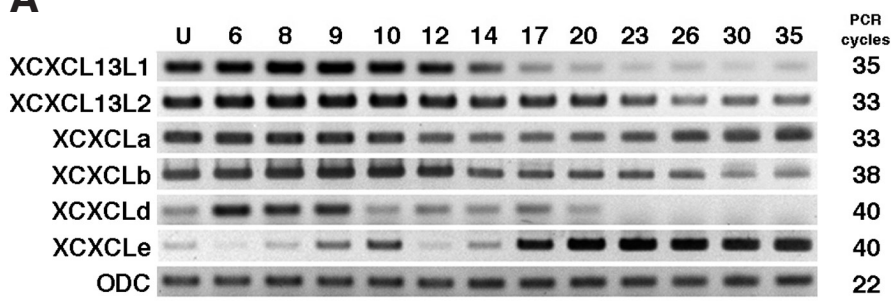

B
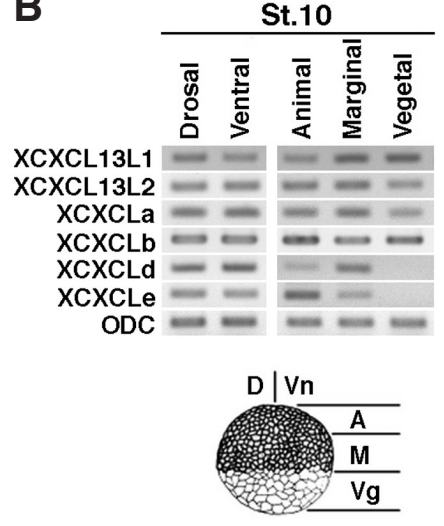
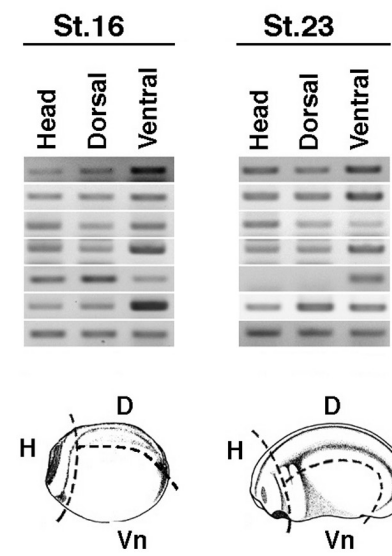

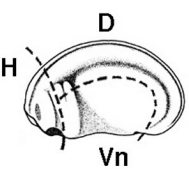

$X C X C R a$ using reverse transcription-polymerase chain reaction (RT-PCR) (see Materials and Methods). The nucleotide sequence of $X C X C R 1 / 2$ is same as one of CXCR2 like protein (AJ312936). The amino acid sequence of XCXCR1/2 is also same as one of Xenopus laevis chemokine (C-X-C motif) receptor 1 (cxcr1) (NCBI NM_001088765.1) that has 2-base-pair mismatches. Therefore we named this gene XCXCR1/2. XCXCLa and XCXCLe contain the ELR motif at the $\mathrm{N}$-terminus of the first cysteine residue, but do not exhibit high identity with mammalian chemokine molecules containing the ELR motif in their amino acid sequence. XCXCLb and XCXCLd do not contain the ELR motif and have low identity with mammalian CXCLs. XCXCL13L1 and XCXCL13L2 do not contain the ELR motif either, but they have slightly higher identity (36.8\% and $35.9 \%$, respectively) with human CXCL13 (NCBI NP_006410.1) (Fig. 1A). The identity between XCXCL13L1 and XCXCL13L2 is not high (37.9\%). The predicted XCXCR proteins contain the seven transmembrane regions that are conserved in GPCR. XCXCR1/2 exhibits 55.8\% and 58.3\% identity with human CXCR1 (NCBI NP_000625.1) and human CXCR2 (NCBI NP_001548.1), respectively; human CXCR1 have a high identity (79.0\%) with human CXCR2. We were not able to find any Xenopus CXCR1- or CXCR2-like genes in the gene databank. These observations suggest that $X C X C R 1 / 2$ is an ancestor gene of both CXCR1 and CXCR2. XCXCR3, XCXCR5, and XCXCR6 have high

\section{A}

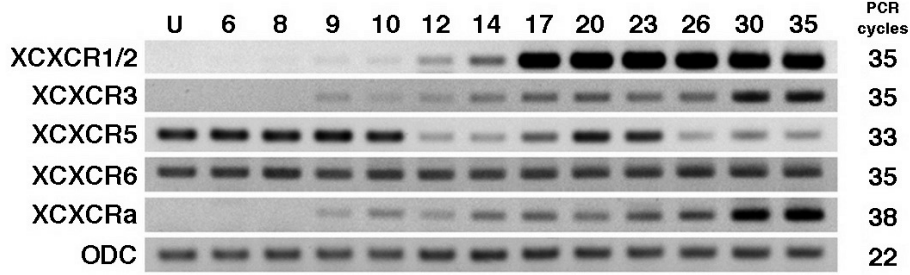

B

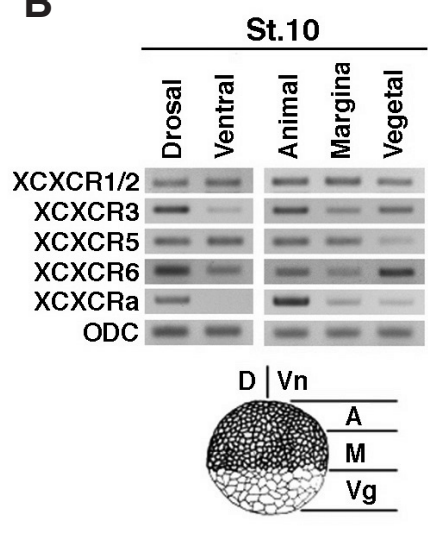

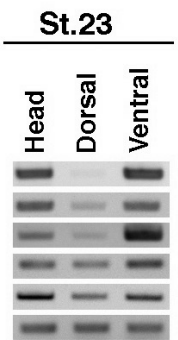

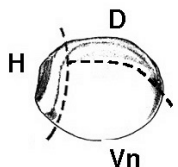

Fig. 2 (left). Expression patterns of Xenopus chemokine ligand transcripts. Reverse transcription-polymerase chain reaction analysis was performed using total RNA extracted from Xenopus embryos at different stages of development and from different regions. Ornithine decarboxylase (ODC) was used as an internal control. (A) Temporal expression patterns. U, unfertilized eggs. The numbers indicate developmental stages. The number of polymerase chain reaction (PCR) cycles is given on the right. (B) Spatial expression patterns. Embryos were dissected at the stages indicated, and dissections were performed as shown in the bottom panels. Abbreviations: $D$, dorsal; Vn, ventral; $A$, animal; $M$, marginal; Vg, vegetal; $H$, head.

Fig. 3 (right). Expression patterns of Xenopus chemokine receptor transcripts. Reverse transcription-polymerase chain reaction analysis was performed using total RNA extracted from Xenopus embryos at different stages of development and from different regions. Ornithine decarboxylase (ODC) was used as an internal control. (A) Temporal expression patterns. U, unfertilized eggs. The numbers indicate developmental stages. The number of polymerase chain reaction (PCR) cycles is given on the right. (B) Spatial expression patterns. Embryos were dissected at the stages indicated, and dissections were performed as shown in the bottom panels. Abbreviations as in Fig. 2. 
identities of $44.8 \%, 47.7 \%$, and $41.7 \%$ with human CXCR3 (NCBI NP_001495.1), CXCR5 (NCBI NP_001707.1), and CXCR6 (NCBI NP_006555.1), respectively (Fig. 1B). XCXCRa does not exhibit high identity with any mammalian CXCR.

Expression of Xenopus CXCL genes during morphogenesis

Because only low levels of Xenopus CXC-type chemokine ligand transcripts were present during early embryogenesis, we could not

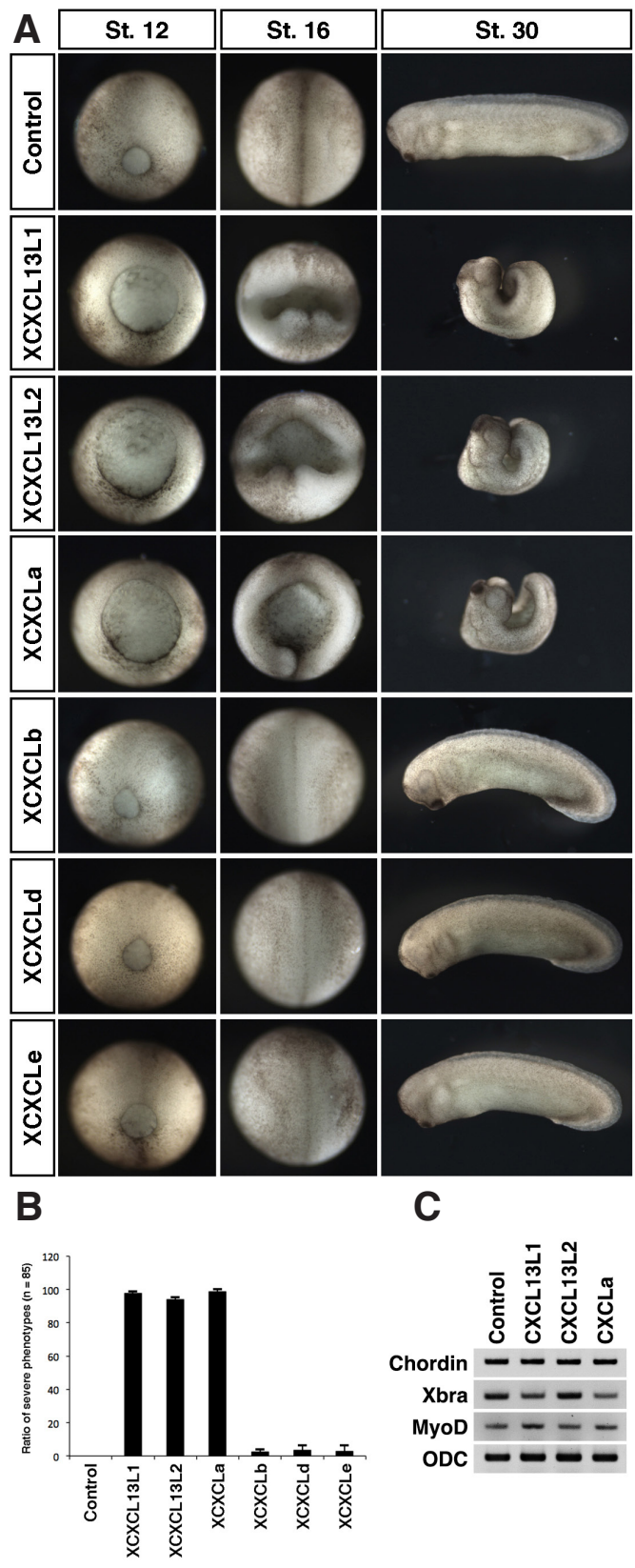

Fig. 4. Phenotypes of Xenopus embryos injected with chemokine ligands into the dorsal side. (A) Phenotypes of the injected embryos. The mRNA of each chemokine ligand (500 pg/blastomere) was injected into two dorsal blastomeres of 4-cell-stage embryos. Left panels, Stage 12, vegetal view; center panels, Stage 16, dorsal view; right panels, Stage 30, lateral view. (B) The ratio of the injected embryos exhibiting gastrulation defects. (C) RT-PCR analysis of mesodermal marker genes. Total RNA for RT-PCR was extracted the dorsal sectors of the injected embryos at stage 10. determine their localization using whole-mount in situ hybridization. Therefore, we investigated the expression patterns of these genes using RT-PCR analysis. Transcripts of XCXCL 13L 1, XCXCL 13L2, $X C X C L b$, and $X C X C L d$ are expressed maternally, with levels decreasing after the gastrula stage. Maternal expression of XCXCLa decreases gradually during the gastrula and neurula stages, and increases again after the tailbud stage. XCXCLe expression has a faint peak at the early gastrula stage and increases after the late neurula stage (Fig. 2A). At the gastrula stage, there is uniform distribution of XCXCL13L1, XCXCL13L2, XCXCLa, and XCXCLb throughout the embryo, whereas the expression of $X C X C L d$ and $X C X C L$ eincreases in the marginal and animal regions, respectively (Fig. 2B, left panel). Transcripts of all the $X C X C L$ genes except $X C X C L a$ are abundant in the ventral region at the later stages of embryogenesis (Fig. 2B, center and right panels).

\section{Expression of Xenopus CXCR genes during early development} $X C X C R 1 / 2, X C X C R 3$, and $X C X C R a$ are expressed zygotically and their expressions increase gradually. Maternal expression of $X C X C R 5$ decreases during the late gastrula and early neurula stages, and increases after the late neurula stage. Expression of $X C X C R 6$ is uniform throughout the early embryonic stages (Fig. 3A). As for CXCL, transcript levels of Xenopus CXC-type chemokine receptors are too low during early embryogenesis to enable their specific localization by whole-mount in situ hybridization. Thus, RTPCR analysis was performed using region-specific RNA sources. $X C X C R 1 / 2$ transcripts were distributed uniformly at the gastrula stage, whereas $X C X C R 3$ and $X C X C R a$ are abundantly expressed in the dorsal animal region. Abundant expression of the XCXCR5 transcript is found in the animal and marginal regions, whereas $X C X C R 6$ is abundant in the dorsal vegetal region (Fig. 3B, left panel). During the later stages of embryogenesis, the transcripts of all $X C X C R$ genes are expressed mainly in the head and ventral regions (Fig. 3B, center and right panels).

\section{Overexpression of XCXCL13L1, XCXCL13L2, and XCXCLa interfered with gastrulation}

Dorsal overexpression of $x S D F 1$-alpha (CXCL12) and XCX$C L C$ inhibited gastrulation and neurulation in Xenopus (Fukui et al., 2007; Goto and Asashima, 2011). To investigate whether the $X C X C L$ genes affect early morphogenesis, we injected each synthetic mRNA encoding the full-length $X C X C L$ gene into two dorsal blastomeres of the 4-cell embryo. The injected embryos developed normally until the formation of the blastopore (data not shown). Injection of XCXCLb, XCXCLd, and XCXCLe mRNA had no effect on embryogenesis at later stages (Fig. 4A). However, overexpression of XCXCL13L1, XCXCL13L2, and XCXCLadelayed dorsal lip closure in the injected embryos. In addition, the neural folds failed to close during neurulation and these embryos had very short anterior-posterior axes (Fig. 4A). Most of XCXCL13L1-, $X C X C L 13 L 2-$ and XCXCLa-injected embryos showed severely gastrulation-inhibited phenotypes (Fig. 4B). When we investigated expressions of mesodermal makergenes, Chordin, Xbra and MyoD in the XCXCL13L1-, XCXCL13L2-and XCXCLa-injected embryos, $X C X C L 13 L 2$ did not affect expression of mesodermal marker genes (Fig. 4C). However, expressions of $X b r a$ were reduced in the XCXCL13L1-and XCXCLa-injected embryos (Fig. 4C). And we confirmed ventral overexpression of XCXCL13L1, XCXCL13L2 or $X C X C L a m R N A d i d$ not affect ventral morphogenesis (Fig. 6A-D,H). 


\section{Overexpression of XCXCR3, XCXCR6, andXCXCRa interfered with gastrulation}

Dorsal overexpression of $x C X C R 4$ inhibited gastrulation and neurulation in Xenopus (Fukui etal., 2007), and CXCL12b/CXCR4a signaling is necessary for zebrafish morphogenesis (Nair and Schilling, 2008). To test whether XCXCR genes have any effect on Xenopus morphogenesis, each synthetic mRNA encoding the full-length $X C X C R$ gene was injected into two dorsal blastomeres of the 4-cell embryo. The injected embryos developed normally

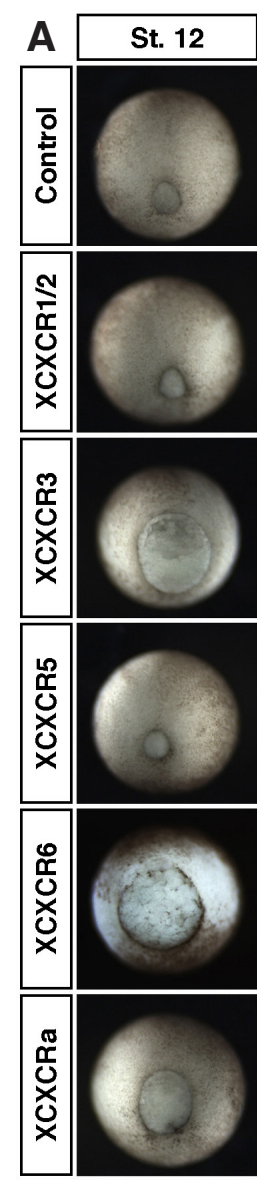

B
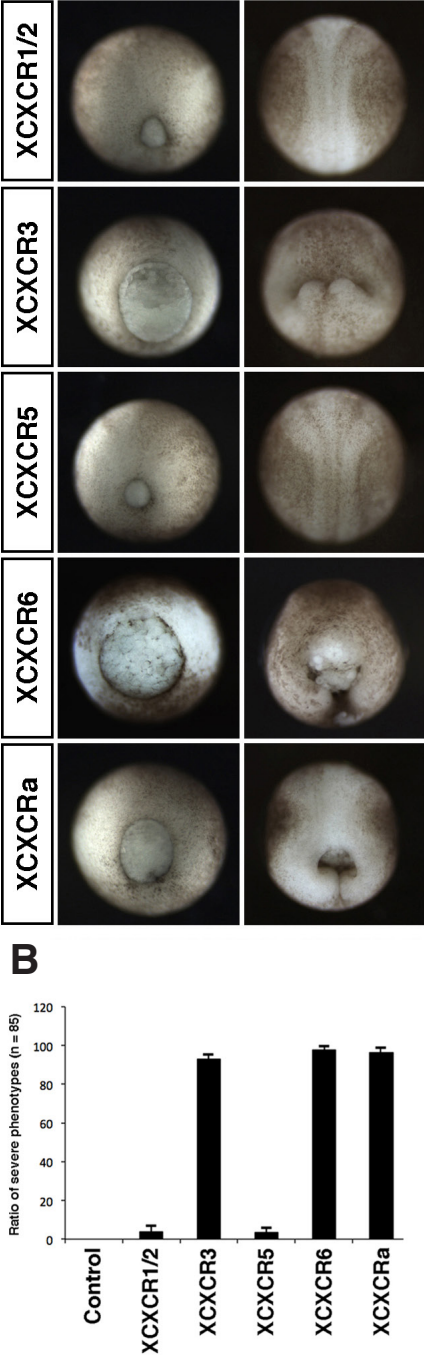
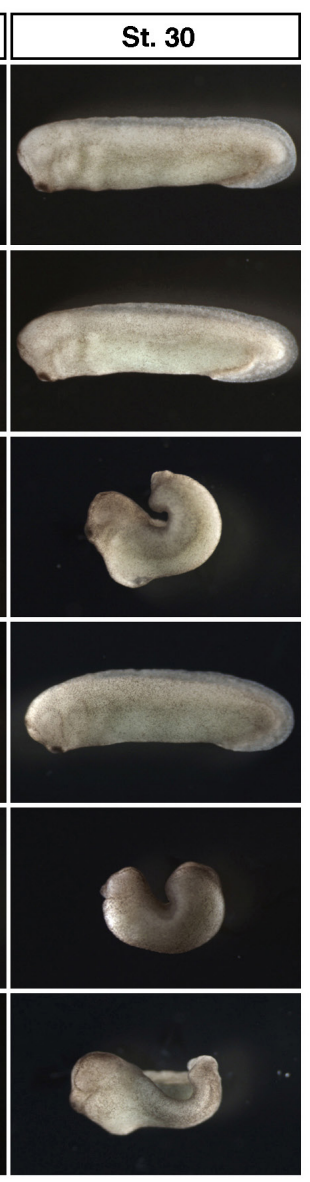

C

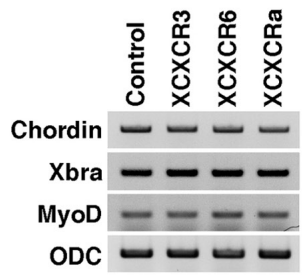

Fig. 5. Phenotypes of Xenopus embryos injected with chemokine receptors into the dorsal side. (A) Phenotypes of the injected embryos. The mRNA of each chemokine receptor (500 pg/blastomere) was injected into two dorsal blastomeres of 4-cell-stage embryos. Left panels, Stage 12, vegetal view; center panels, Stage 16, dorsal view; right panels, Stage 30 , lateral view. (B) The ratio of the injected embryos exhibiting gastrulation defects. (C) RT-PCR analysis of mesodermal marker genes. Total RNA for RT-PCR was extracted the dorsal sectors of the injected embryos at stage 10. until the formation of the blastopore (data not shown). Injection of $X C X C R 3, X C X C R 6$, and $X C X C R a$ mRNA interfered with gastrulation and neurulation (Fig. 5A). These embryos also had very short anterior-posterior axes and widely opened neural tubes (Fig. 5A), similar to that seen following injection of XCXCL 13L1, XCXCL13L2, and $X C X C L a$ (Fig. 4A). Severely gastrulation-inhibited phenotypes were shown by a high incidence in the $X C X C R 3-, X C X C R 6$-, and $X C X C R$-injected embryos (Fig. 5B). Expressions of mesodermal maker genes were unchanged in the XCXCR3-, XCXCR6-, and $X C X C R$-injected embryos (Fig. 5C). When we injected $X C X C R 3$, $X C X C R 6$ or $X C X C R a$ mRNA into two ventral blastomeres of the 4-cell embryo, $X C X C R 6$ interfered with the invagination of ventral side (Fig. 6 A,F,H). However ventral injection of $X C X C R 3$ and $X C X C R a$ did not affect ventral morphogenesis (Fig. $6 \mathrm{E}, \mathrm{G}, \mathrm{H}$ ).

\section{Discussion}

In mammals, each chemokine receptor binds with one or more chemokine ligands (Zlotnik and Yoshie, 2000; Lasagni et al., 2003; Wang et al., 2005; Agostini et al., 2005; Naumann et al., 2010). With the exception of XCXCRa, Xenopus CXC-type chemokine receptors exhibit high identity with mammalian receptors. Specifically, the amino acid sequences of Xenopus CXCL12 (SDF1) and CXCL14 exhibit high identity with their mammalian homologues, and their expression patterns are partly conserved in vertebrates (Fukui et al., 2007; Park et al., 2009). The interaction between CXCL12 (SDF1) and CXCR4 is particularly conserved in vertebrates. On this basis, we considered that Xenopus CXC-type chemokine ligands would exhibit high identity with homologous mammalian ligands that interact with mammalian chemokine receptors. However, the amino acid sequences of Xenopus CXC-type chemokine ligands that were characterized in the present study exhibit only low identity with the mammalian ligands, and we could not find XenopuscDNA sequences exhibiting high identity with mammalian chemokine ligands in the gene databank. These findings suggest that most of the Xenopus CXC-type chemokine ligands may have evolved specifically.

Dorsal cell movements are important for early morphogenesis (Keller and Tibbetts, 1989; Winklbauer, 1990), and chemokine molecules play important roles in cell migration during morphogenesis (Doitsidou et al., 2002; Fukui et al., 2007; Nair and Schilling, 2008; Goto and Asashima, 2011). It has been previously reported that XenopusCXCR 4 is expressed in the dorsal mesendodermal region and that CXCL12(SDF1)/CXCR4 signaling mediates the directional movement of mesendodermal cells during Xenopus gastrulation (Fukui et al., 2007). In the present study, we demonstrated that dorsal overexpression of $X C X C R 3$ and $X C X C R a$ interfered with gastrulation (Fig. 5), and that the $X C X C R 3$ and $X C X C R$ a transcripts are expressed dorsally during the gastrula stage (Fig. 3). Moreover, ventral overexpression of $X C X C R 3$ and $X C X C R a$ did not affect morphogenesis (Fig. 6). These suggest that $X C X C R 3$ and $X C X$ $C R a$ might play main roles in dorsal morphogenesis. On the other hand, overexpression of XCXCR6 interfered with morphogenesis at the dorsal and ventral side (Fig. 5, 6), and expression level of $X C X C R 6$ at the ventral side is higher than those of $X C X C R 3$ and $X C X C R a$ at the gastrula stage (Fig. 3). These results suggest that $X C X C R 6$ might function on both dorsal and ventral side.

Overexpression of XCXCL13L1, XCXCL13L2, and XCXCLaalso interfered with gastrulation (Fig. 4), but the transcripts of these genes 
are uniformly expressed at the gastrula stage. Xenopus CXCL12 (SDF1), which attracts CXCR4-expressing mesendodermal cells during gastrulation, is also expressed uniformly in the ectodermal region during the gastrula stage (Fukui et al., 2007). Conversely, $X C X C L C$ expression in the midline region during gastrulation affects lateral-medial directional tissue convergence (Goto and Asashima, 2011). Thus, there are variations in the expression patterns of transcripts for Xenopus chemokine ligands that affect cell movements, rather than in the expression of chemokine receptors. Moreover, ventral injection of XCXCL13L1, XCXCL13L2, and XCXCLa did not affect morphogenesis (Fig. 6). We suggest that the protein distribution of the secreted chemokine ligands or the pattern of expression of their receptors is more important than the expression patterns of ligand transcripts.

Overexpression of XCXCL13L2, XCXCR3, XCXCR6 and $X C X C R a$ interfered with gastrulation but did not affect expressions of mesodermal marker genes. We suggest that these four chemokine molecules might contribute to only cell movements during early morphogenesis. On the other hand, overexpression of XCXCL13L1 and XCXCLa interfered with morphogenesis and reduced $X b r a$ expression in the injected embryos. These suggest that cell differentiation affected by XCXCL13L1 and XCXCLa would cause defects of morphogenesis in part.

In mammals, CXCR1 and CXCR2 interact with ELR(+) CXCtype chemokine ligands (Romagnani et al., 2004). In the present
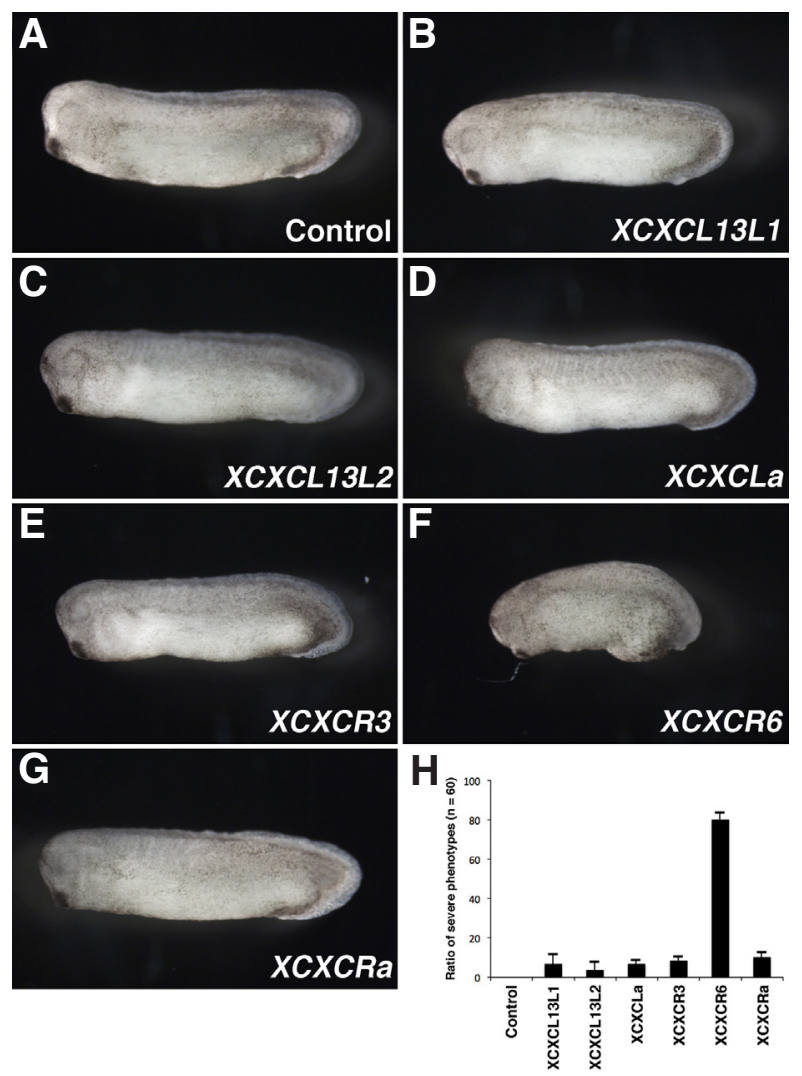

Fig. 6. Phenotypes of Xenopus embryos injected with chemokine receptors into the dorsal side. (A-G) Phenotypes of the injected embryos. (A) Control. (B) XCXCL13L1. (C) XCXCL13L2. (D) XCXCLa. (E) XCXCR3. (F) XCXCR6. (G) XCXCRa. (H) The ratio of the injected embryos exhibiting ventral morphogenesis defects.
TABLE 1

\section{PRIMER PAIRS USED TO GENERATE FULL-LENGTH CDNA OF EACH GENE FOR CLONING}

\begin{tabular}{|c|c|}
\hline Gene & Primer \\
\hline XCXCL13L1 & $\begin{array}{l}\text { Forward: 5'-CCCCGAATTCTCAAGGTACAATGAAGTACA-3' } \\
\text { Reverse: 5'-CCCCCTCGAGTTAAGTATTATTTTCACTTT-3' }\end{array}$ \\
\hline$X C X C L 13 L 2$ & $\begin{array}{l}\text { Forward: 5'-CCCCATCGATCAGATCCAGTATGAGCATGA-3' } \\
\text { Reverse: 5'-CCСTCTCGAGTCATATTGGTGTACTGTCTG-3' }\end{array}$ \\
\hline XCXCLa & $\begin{array}{l}\text { Forward: 5'-ACCCATCGATAATCTCCAACATGCAGTGCC-3' } \\
\text { Reverse: 5'-CCCCCTCGAGTCATTTCTTCTGTGAATTCC-3' }\end{array}$ \\
\hline$X C X C L b$ & $\begin{array}{l}\text { Forward: 5'-CCCCGAATTCAACAGCCAAAATGAGTGCTA-3' } \\
\text { Reverse: 5'-CCAACTCGAGTTAGCGATCTGTTTGAGTCA-3' }\end{array}$ \\
\hline$X C X C L d$ & $\begin{array}{l}\text { Forward: 5'-CCCCGAATTCACTGAAAGCTATGACACTGT-3' } \\
\text { Reverse: 5'-CCTTCTCGAGTGCCAAAGCATCGAGAGATA-3' }\end{array}$ \\
\hline XCXCLe & $\begin{array}{l}\text { Forward: 5'-CCCCGAATTCCCAATTTAACCATGGAAACCA-3' } \\
\text { Reverse: 5'-CCCTCTCGAGTTAAAGAGCAGAAACAGGTG-3' }\end{array}$ \\
\hline$X C X C R 1 / 2$ & $\begin{array}{l}\text { Forward: 5'-CCCCATCGATATGTCCTTTAATTTTGATGG-3' } \\
\text { Reverse: 5'-CCCCGAATTCTTAGAGTGTGTTGGATGTGT-3' }\end{array}$ \\
\hline XCXCR3 & $\begin{array}{l}\text { Forward: 5'-CCCCGAATTCACTTCTACAAATGCAAAGTG-3' } \\
\text { Reverse: 5'-TCCCCTCGAGTCACATTGCAGATACTGTAG-3' }\end{array}$ \\
\hline XCXCR5 & $\begin{array}{l}\text { Forward: 5'-GAAAGAATTCGAGTGGAGGAATGGAGTCTA-3' } \\
\text { Reverse: 5'-GGGGCTCGAGTCATCATTAAAAAGGCACAC-3' }\end{array}$ \\
\hline XCXCR6 & $\begin{array}{l}\text { Forward: 5'-CCGAATTCCGTAAATAATATGACAAACAACACAGAAGA-3' } \\
\text { Reverse: 5'-GGGGCTCGAGTTACAACTGGTTCATACTAA-3' }\end{array}$ \\
\hline XCXCRa & $\begin{array}{l}\text { Forward: 5'-GGGGGAATTCTGTGAGCAATATGGCAGAAG-3' } \\
\text { Reverse: 5'-TTTGCTCGAGCAGCAAATGTGAAATAGACC-3' }\end{array}$ \\
\hline
\end{tabular}

study, only XCXCLa has the ELR motif and its overexpression inhibited gastrulation (Fig. 5). However, overexpression of $X C X-$ $C R 1 / 2$ had no effect on morphogenesis (Fig. 5). We suggest that the candidate receptor for XCXCLa is not XCXCR1/2, but may be another CXC-type receptor, including XCXCR4 or XCXCR7. Human CXCL13 interacts with CXCR5 (Legler et al., 1998). Both XCXCL13L1 and XCXCL13L2 have slightly higher identities with human CXCL13 (Fig. 1A), and their overexpression affected early morphogenesis in Xenopus (Fig. 4). However, XCXCR5 had no effect on morphogenesis (Fig. 5). These suggest that $X C X C R 5$ is not a candidate chemokine receptor for $X C X C L 13 L 1$ and $X C X C L 13 L 2$. CXCR3 interacts with several ELR(-)-CXCtype chemokine ligands, such as CXCL4, CXCL9, CXCL10, and CXCL11 (Romagnani et al., 2004), and CXCR6 selectively binds CXCL16 in mammals (Agostini et al., 2005). However, we could not find any homologous Xenopus ligands for CXCR3 and CXCR6 in the gene databank. Regardless of the differences in amino acid sequences between mammalian and Xenopus CXCL, the Xenopus CXC-type chemokine ligands may have functional redundancies with mammalian ligands.

\section{Materials \& Methods}

\section{Cloning of Xenopus CXC-type chemokine ligands and receptors}

The cDNA of each gene was generated by RT-PCR of RNA samples from Stage 10 embryos. Total RNA was prepared using TRIzol (Invitrogen). cDNA synthesis was carried out using Moloney murine leukemia virus reverse transcriptase (Invitrogen). Table 1 lists the primer pairs used for RT-PCR cloning of chemokine ligands and receptors. PCR was performed using KOD-Plus DNA polymerase (TOYOBO). In order to obtain the full-length cDNA of chemokine ligands and receptors, the primers were designed with reference to the sequences of BG018851 for XCXCL13L1, CF342082 for XCXCL13L2, CB199271 for XCXCLa, BC130085 for XCXCLb, AW644053 for XCXCLd, CF548813 for XCXCLe, AJ312936 for $X C X C R 1 / 2, B C 157471$ for $X C X C R 6$. The primers to obtain the full-length cDNA of $X C X C R 3$ were designed with reference to the 
TABLE 2

\section{PRIMER PAIRS USED IN RT-PCR ANALYSIS}

\begin{tabular}{ll} 
Gene & Primer \\
\hline XCXCL13L1 & Forward: 5'-TTGCTGTCCTGCTGTGCTTA-3' \\
& Reverse: 5'-GCTCCAGATCCCTTCCAATT-3' \\
XCXCL13L2 & Forward: 5'-TGCTGTGCTGTCTGTCATTG-3' \\
& Reverse: 5'-TATTGGTGTACTGTCTGCCG-3' \\
XCXCLa & Forward: 5'-ACCGTATCAACCGCCTTTCA-3' \\
& Reverse: 5'-GACTGCTGAATGAAAGAGGG-3' \\
XCXCLb & Forward: 5'-AATCTGGGGAACGTGTGTGT-3' \\
& Reverse: 5'-GAGAATTTGGAGCATGGCC-3' \\
XCXCLd & Forward: 5'-GCACGAGGAAATTGAGACCA-3' \\
& Reverse: 5'-TCTCTGTTGCCTGCTTGTAG-3' \\
XCXCLe & Forward: 5'-GGAAACCAAGAGAAGTGTCC-3' \\
& Reverse: 5'-CAAGCAGGTTCCACTCAATG-3' \\
XCXCR1/2 & Forward: 5'-GACACTTGGTAGGCTTCTTC-3' \\
XCXCR3 & Reverse: 5'-AGCATAACGGGCCAGAAAAG-3' \\
& Forward: 5'-GAAACAGAAAGCCCTACGAG-3' \\
XCXCR5 & Reverse: 5'-AGTTGAAGGTTTGGCTGGAG-3' \\
XCXCR6 & Forward: 5'-GGGATTCTGCTATGCTCACA-3' \\
XCXCRa & Reverse: 5'-CCATTTTCAGAGTCAGTGGC-3' \\
Ornithine decarboxylase & Forward: 5'-ACTCTCACCGACACCTTCAT-3' \\
(ODC) & Reverse: 5'-GCAAGTAACAGCGACACCAA-3' \\
\hline
\end{tabular}

nucleotide sequence of $\mathrm{BC} 073571$. There are 3-amino acid mismatches between XCXCR3 and the translated sequence of $B C 073571$. The primers to obtain the full-length CDNA of XCXCR5 were designed with reference to the nucleotide sequences of BX845251 for 5'-region and BE132148 for 3'-region of $X C X C R 5$. The primers to obtain the full-length cDNA of $X C X C R a$ were designed with reference to the nucleotide sequences of BX850143 for 5'-region and BI313710 for 3'-region of XCXCRa. The cDNA fragments were subcloned into a modified pCS2+ vector as previously reported (Goto et al., 2008).

\section{RT-PCR analyses}

Total RNA was prepared using TRIzol (Invitrogen). cDNA synthesis was carried out using Moloney murine leukemia virus reverse transcriptase (Invitrogen). PCR was performed using rTaq DNA polymerase (TAKARA). Table 2 lists the primer pairs used for RT-PCR analyses of expression patterns of CXC-type chemokine ligands and receptors, which were performed as previously described (Suzawa et al., 2007) at least in triplicate. Xenopus embryonic Ornithine decarboxylase (ODC) was used for normalization of cDNA samples. For RT-PCR analyses of mesodermal marker genes, the sequences of the primer pairs were as follows. Chordin: Forward 5'-TTTCCTGTACCAACCCAATCC-3'; Reverse 5'-GGCAGGATTTAGAGTTGCTTC-3'. Xbra: Forward 5'-ATAGCAGTGACCGCATACCAG-3'; Reverse 5'-GCTGGCATTTGAAGGGTAGAC-3'. MyoD: Forward 5'-CCGGTTCTGGAACATTACAG-3'; Reverse 5'-AGGGGAAGTTCATGGATTGG-3'.

\section{Microinjection of $m R N A s$}

Capped mRNAs were synthesized from linearized vectors using Thermo T7 RNA polymerase (TOYOBO). The mRNA of each Xenopus chemokine ligand was microinjected into the marginal zones of two dorsal or ventral blastomeres of 4-cell embryos (500 pg/blastomere).

\section{Acknowledgements}

This work was supported by Grants-in-Aid for scientific research from the Ministry of Education, Science, Sports and Culture of Japan.

\section{References}

AGOSTINI C., CABRELLE A., CALABRESE F., BORTOLI M., SCQUIZZATO E., CARRARO S., MIORIN M., BEGHĖ B., TRENTIN L., ZAMBELLO R., FACCO M., and SEMENZATO G. (2005). Role for CXCR6 and its ligand CXCL16 in the pathogenesis of T-cell alveolitis in sarcoidosis. Am. J. Respir. Crit. Care. Med. 172: 1290-1298.

ALLENS. J., CROWNS. E., and HANDELT. M. (2007). Chemokine: receptor structure, interactions, and antagonism. Annu. Rev. Immunol. 25: 787-820.

DOITSIDOU M., REICHMAN-FRIED M., STEBLER J., KÖPRUNNER M., DÖRRIES J., MEYER D., ESGUERRA C. V., LEUNG T., and RAZ E. (2002). Guidance of primordial germ cell migration by the chemokine SDF-1. Cell 111: 647-659.

FUKUI A., GOTO T., KITAMOTO J., HOMMA M., and ASASHIMA M. (2007). SDF-1 alpha regulates mesendodermal cell migration during frog gastrulation. Biochem. Biophys. Res. Commun. 354: 472-477.

GOTOT., KELLER R., and ASASHIMAM. (2008). Concentrations of TATAbox-binding protein (TBP)-type genes affect chordamesodermal gene expression. Int. J. Dev. Biol. 52: 371-375.

GOTO T., and ASASHIMAM. (2011). Chemokine ligand Xenopus CXCLC (XCXCLC) regulates cell movements during early morphogenesis. Dev. Growth Differ. 53 : 971-981.

HARA T., and TANEGASHIMA K. (2012). Pleiotropic functions of the CXC-type chemokine CXCL14 in mammals. J. Biochem. 151: 469-476.

HIRAOKAN., YAMAZAKI-ITOH R., INO Y., MIZUGUCHIY., YAMADA T., HIROHASHI S., and KANAI Y. (2011). CXCL17 and ICAM2 are associated with a potential anti-tumor immune response in early intraepithelial stages of human pancreatic carcinogenesis. Gastroenterology 140: 310-321.

KELLER R., and TIBBETTS P. (1989). Mediolateral cell intercalation in the dorsal, axial mesoderm of Xenopus laevis. Dev. Biol. 131: 539-549.

LAING K. J., and SECOMBES C. J. (2004). Chemokines. Dev. Comp. Immunol. 28: 443-460.

LASAGNI L., FRANCALANCI M., ANNUNZIATO F., LAZZERI E., GIANNINI S., COSMI L., SAGRINATI C., MAZZINGHI B., ORLANDO C., MAGGI E., MARRA F., ROMAGNANI S., SERIO M., and ROMAGNANI P. (2003). An alternatively spliced variant of $C X C R 3$ mediates the inhibition of endothelial cell growth induced by IP-10, Mig, and I-TAC, and acts as functional receptor for platelet factor $4 . \mathrm{J}$. Exp. Med. 197: 1537-1549.

LEGLER D. F., LOETSCHER M., ROOS R. S., CLARK-LEWIS I., BAGGIOLINI M., and MOSER B. (1998). B cell-attracting chemokine 1, a human CXC chemokine expressed in lymphoid tissues, selectively attracts B lymphocytes via BLR1/ CXCR5. J. Exp. Med. 187: 655-660.

MAHABALESHWAR H., BOLDAJIPOUR B., RAZ E. (2008). Killing the messenger: The role of $\mathrm{CXCR} 7$ in regulating primordial germ cell migration. Cell. Adh. Migr. 2: 69-70.

NAUMANN U., CAMERONI E., PRUENSTER M., MAHABALESHWAR H., RAZ E., ZERWES H. G., ROTA., and THELEN M. (2010). CXCR7 functions as a scavenger for CXCL12 and CXCL11. PLoS One 5: e9175.

NAIR S., and SCHILLING T. F. (2008). Chemokine signaling controls endodermal migration during zebrafish gastrulation. Science 322: 89-92.

PARK B. Y., HONG C. S., SOHAIL F. A., and SAINT-JEANNET J. P. (2009). Developmental expression and regulation of the chemokine CXCL14 in Xenopus. Int. J. Dev. Biol. 53: 535-540.

ROMAGNANI P., LASAGNI L., ANNUNZIATO F., SERIO M., and ROMAGNANI S. (2004). CXC chemokines: The regulatory link between inflammation and angiogenesis. Trends Immunol. 25: 201-209.

SUZAWA K., YUKITA A., HAYATA T., GOTO T., DANNO H., MICHIUE T., CHO K.W., and ASASHIMA M. (2007). Xenopus glucose transporter 1 (xGLUT1) is required for gastrulation movement in Xenopus laevis. Int. J. Dev. Biol. 51: 183-190.

WANG J., ADELSON D. L., YILMAZ A., SZE S. H., JIN Y., and ZHU J.J. (2005). Genomic organization, annotation, and ligand-receptor inferences of chicken chemokines and chemokine receptor genes based on comparative genomics. BMC Genomics 6: 45.

WINKLBAUER R. (1990). Mesodermal cell migration during Xenopus gastrulation. Dev. Biol. 142: 155-168.

ZLOTNIK A., and YOSHIE O. (2000). Chemokines: A new classification system and their role in immunity. Immunity 12: 121-127. 


\section{Further Related Reading, published previously in the Int. J. Dev. Biol.}

CXCL14 expression during chick embryonic development

Christopher T. Gordon, Christine Wade, Inigo Brinas and Peter G. Farlie

Int. J. Dev. Biol. (2011) 55: 335-340

Paracrine regulation of angiogenesis by different cell types in the aorta ring model Roberto F. Nicosia, Penelope Zorzi, Giovanni Ligresti, Ann Morishita and Alfred C. Aplin Int. J. Dev. Biol. (2011) 55: 447-453

\section{CXCL14 expression during chick embryonic development}

Christopher T. Gordon, Christine Wade, Inigo Brinas and Peter G. Farlie Int. J. Dev. Biol. (2011) 55: 335-340

Local regulation of implantation at the human fetal-maternal interface

Evdokia Dimitriadis, Guiying Nie, Natalie J. Hannan, Premila Paiva and Lois A. Salamonsen Int. J. Dev. Biol. (2010) 54: 313-322

Developmental expression and regulation of the chemokine CXCL14 in Xenopus Byung-Yong Park, Chang-Soo Hong, Faraz A. Sohail and Jean-Pierre Saint-Jeannet Int. J. Dev. Biol. (2009) 53: 535-540

Stromal-derived factor-1 (SDF-1) expression during early chick development Rizwan Rehimi, Nargis Khalida, Faisal Yusuf, Fangping Dai, Gabriela Morosan-Puopolo and Beate Brand-Saberi

Int. J. Dev. Biol. (2008) 52: 87-92

The countercurrent principle in invasion and metastasis of cancer cells. Recent insights on the roles of chemokines

Ghislain Opdenakker and Jo Van Damme

Int. J. Dev. Biol. (2004) 48: 519-527

The chemokine network in cancer - much more than directing cell movement Hagen Kulbe, Neil R. Levinson, Fran Balkwill and Julia L. Wilson Int. J. Dev. Biol. (2004) 48: 489-496

5 yr ISI Impact Factor $(2011)=2.959$

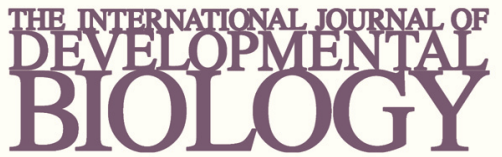

Volume 54 Nos. $6 / 7$
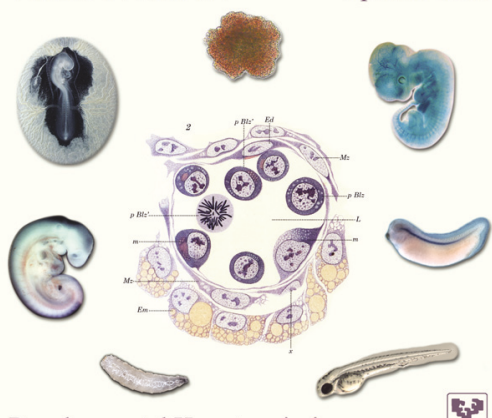

Developmental Hematopoiesis

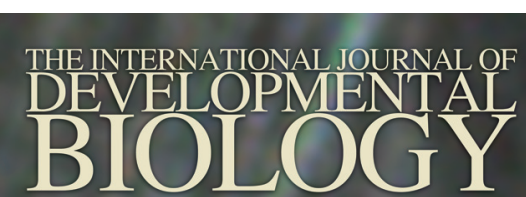

Volume 56 Nos. 1/2/3

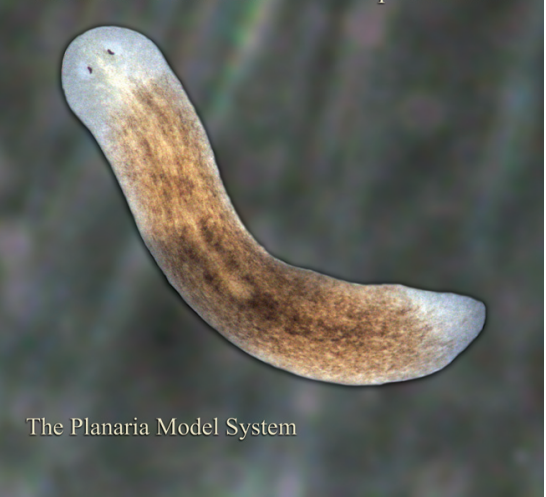

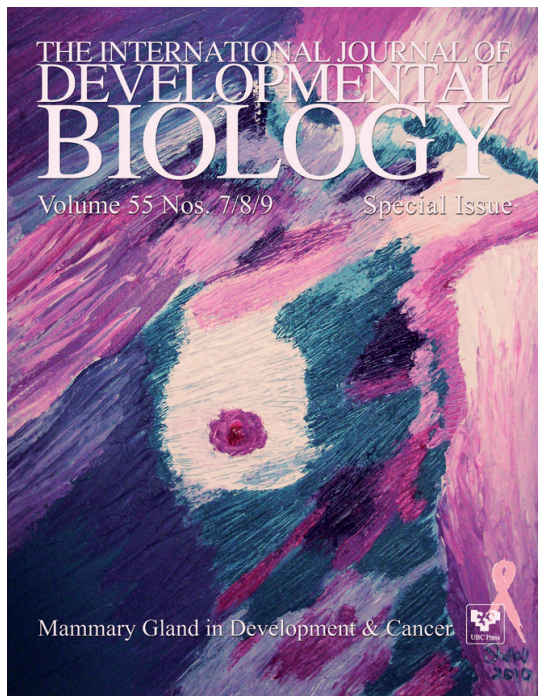
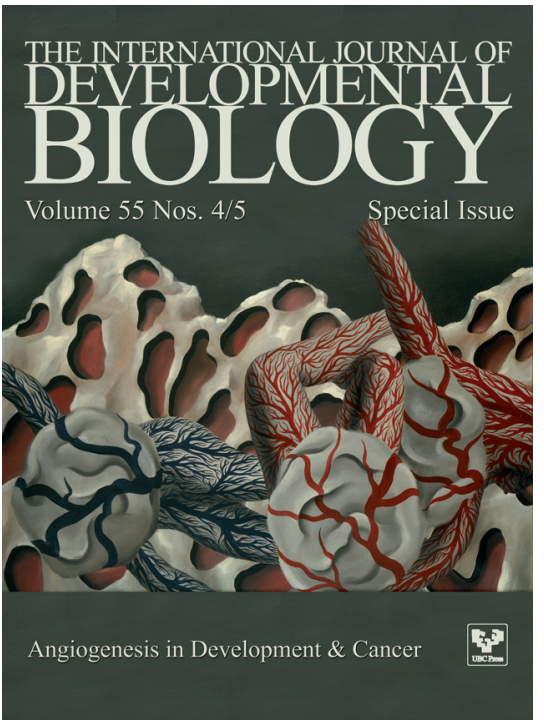